\title{
First Preparation of Nanocrystalline Zinc Silicate by Chemical Vapor Synthesis Using an Organometallic Single-Source Precursor
}

\author{
A. Roy,${ }^{[a]}$ S. Polarz ${ }^{[b]}$ S. Rabe,${ }^{[b]}$ B. Rellinghaus, ${ }^{[c]}$ H. Zähres, ${ }^{[c]}$ F. E. Kruis, ${ }^{*[a]}$ and \\ Matthias Driess ${ }^{*[b]}$
}

\begin{abstract}
A method is presented to prepare nanocrystalline $\alpha-\mathrm{Zn}_{2} \mathrm{SiO}_{4}$ with the smallest crystal size reported so far for this system. Our approach combines the advantages of organometallic single-source precursor routes with aerosol processing techniques. The chemical design of the precursor enables the preferential formation of pure zinc silicates. Since gas-phase synthesis reduces intermolecular processes, and keeps the particles small, zinc silicate was synthesized from the volatile organometallic precursor [ $\left.\left\{\mathrm{MeZnOSiMe}_{3}\right\}_{4}\right]$, possessing a $Z n$-methyl- and $O$-silylsubstituted $\mathrm{Zn}_{4} \mathrm{O}_{4}$-heterocubane framework (cubane), under oxidizing conditions, using the chemical vapor synthesis (CVS) method. The products ob-
\end{abstract}

tained under different process conditions and their structural evolution after sintering were investigated by using various analytical techniques (powder X-ray diffraction, transmission electron microscopy, EDX analysis, solid-state NMR, IR, Raman, and UV/ Vis spectroscopy). The deposited aerosol obtained first (processing temperature $750{ }^{\circ} \mathrm{C}$ ) was amorphous, and contained agglomerates with primary particles of $12 \mathrm{~nm}$ in size. These primary particles can be described by a [Zn-O-

Keywords: aerosol technology • chemical vapor synthesis - metal oxides • nanoparticles • singlesource precursors

\section{Introduction}

In recent years there has been a great deal of research concerning the use of organometallic precursors for the formation of inorganic materials. ${ }^{[1]}$ The advantages of using organometallic precursors are twofold. First, it is possible to

[a] Dr. A. Roy, Priv.-Doz. Dr. F. E. Kruis

Process and Aerosol Measurement Technology, Department of Electrical Engineering and Information Technology University Duisburg-Essen, 47057 Duisburg (Germany) Fax: (+49)203-3793268

E-mail: e.kruis@uni-duisburg.de

[b] Dr. S. Polarz, Dr. S. Rabe, Prof. Dr. M. Driess Department of Inorganic Chemistry Ruhr-University Bochum, 44801 Bochum (Germany) Fax: (+49) 234-14378 E-mail: matthias.driess@rub.de

[c] Dr. B. Rellinghaus, H. Zähres Experimental Physics, Institute of Physics University Duisburg-Essen, Lotharstrasse-1, 47048 Duisburg (Germany)
Si] phase without long-range order. The deposit obtained at $900^{\circ} \mathrm{C}$ contained particles with embedded nanocrystallites $(3-5 \mathrm{~nm})$ of $\beta-\mathrm{Zn}_{2} \mathrm{SiO}_{4}$, $\mathrm{Zn}_{1.7} \mathrm{SiO}_{4}$, and $\mathrm{ZnO}$ in an amorphous matrix. On further ageing, the as-deposited particles obtained at $900^{\circ} \mathrm{C}$ form $\alpha-\mathrm{Zn}_{2} \mathrm{SiO}_{4}$ imbedded in amorphous $\mathrm{SiO}_{2}$. The crystallite sizes and primary particle sizes in the formed $\alpha-\mathrm{Zn}_{2} \mathrm{SiO}_{4}$ were found to be below $\sim 50 \mathrm{~nm}$ and mainly spherical in morphology. A gas-phase mechanism for the particle formation is proposed. In addition, the solid-state reactions of the same precursor were studied in detail to investigate the fundamental differences between a gas-phase and a solid-state synthesis route. design and synthesize single-source precursors with a specific stoichiometry so that a desired compound, composite, or doped material can be obtained without process-specific problems such as mixing of reactants. Thus, ideal dispersion of elements on a molecular scale can be reached. Second, conversion of a single organometallic precursor into the desired product is more controllable and takes place at lower temperatures than for multicomponent systems in most cases. Not only can the stoichiometry be predetermined, but reaction pathways can also be controlled through a suitable choice of the molecular architecture of the precursor. Thus, finding new organometallic single-source precursors, with which to synthesize tailored materials, is of high relevance.

Herein we investigate the formation of zinc silicate by such an organometallic single-source precursor route. Zinc orthosilicate, $\alpha-\mathrm{Zn}_{2} \mathrm{SiO}_{4}\left(\alpha\right.$-willemite), ${ }^{[2 \mathrm{a}]}$ doped with divalent manganese ions, is of extraordinary interest as it is commercially used as a green-emitting phosphor material ${ }^{[2 b]}$ for plasma display panels. ${ }^{[3]}$ The $\alpha-\mathrm{Zn}_{2} \mathrm{SiO}_{4}$ phase is typically produced by solid-state methods that require high-temperature processes with long processing times. ${ }^{[3 a, b, 4]}$ One task is 
therefore to find routes for the production of $\mathrm{Zn}_{2} \mathrm{SiO}_{4}$ that are more energy efficient and easier in terms of processing.

In addition, it is of special interest to prepare nanoscaled zinc-silicate particles to improve the dispersion and luminescence properties of related phosphor materials. Quantum confinement in nanocrystalline materials can result in an improvement of luminescence properties, as has been found for many phosphor materials. ${ }^{[5]}$ Additionally, nanoscaled phosphor materials offer the potential for preparing smoother films with higher packing densities than for conventional micron-sized phosphors. ${ }^{[3, \mathrm{~d}]}$ In conventional powder processing, grinding and milling are applied to obtain the size desired for applications. This kind of processing leads to particles with irregular morphologies and low luminescence efficiencies. Several investigations have been performed to develop alternative chemical procedures towards compositionand morphology-controlled $\alpha$-willemite particles and thin films. For instance, methods have been reported for the synthesis of particles of pure and doped $\alpha-\mathrm{Zn}_{2} \mathrm{SiO}_{4}$ using solgel synthesis, ${ }^{[6]}$ low-temperature synthesis in an aqueous medium, ${ }^{[7]}$ hydrothermal synthesis, ${ }^{[8]}$ a polymeric precursor route, ${ }^{[9]}$ and spray pyrolysis. ${ }^{[10]}$ However, examples of truly nanosized zinc silicate are still very rare, as produced $\mathrm{Zn}_{2} \mathrm{SiO}_{4}$ particles range from several hundred nanometers to several micrometers in most cases. Su et al. prepared irregularly shaped $\alpha-\mathrm{Zn}_{2} \mathrm{SiO}_{4}$ particles in the range of $50-100 \mathrm{~nm}$ using solid-state thermolysis of a nonvolatile oxygen-rich molecular alkoxy(siloxy)zinc precursor. ${ }^{[9]}$ Very recently, Tani et al. reported the synthesis of $\alpha-\mathrm{Zn}_{2} \mathrm{SiO}_{4}$ nanoparticles with crystallite size below $100 \mathrm{~nm}$ by post-calcination of flamemade zinc oxide-silica composites. ${ }^{[10 \mathrm{~d}]}$

Gas-phase synthesis of particles by chemical means (chemical vapor synthesis, CVS ${ }^{[11]}$ is promising because of its simplicity, easy scale-up and continuous processing. CVS is performed at higher process temperatures, higher precursor partial pressure, and longer residence time than chemical vapor deposition (CVD), and thus results in particle formation. ${ }^{[11]}$ Particles formed by CVS are generally nanocrystalline with a relatively narrow size distribution. Thus, use of a suitable organometallic precursor under CVS processing conditions should produce nanosized particles of a desired compound. However, the availability of suitable organometallic single-source precursors is still limited. Only one volatile precursor, $\left[\mathrm{Zn}\left\{\mathrm{NC}\left(\mathrm{CH}_{3}\right)_{3}\left[\mathrm{Si}\left(\mathrm{CH}_{3}\right)_{3}\right]\right\}_{2}\right]$, has so far been reported for the preparation of $\mathrm{Zn}_{2} \mathrm{SiO}_{4}{ }^{[12]}$

The present work is devoted to the detailed investigation of the CVS of $\alpha$-willemite nanoparticles using a volatile organometallic precursor, which is described in more detail below. Besides the investigation of the formation of $\mathrm{Zn}_{2} \mathrm{SiO}_{4}$, it is also very interesting to explore the fundamental differences between a solid-state and a gas-phase decomposition route. The decomposition in the solid state is essentially a process with a high density of precursor molecules, for which diffusional processes are the dominating mechanism. CVS, on the other hand, uses the precursor highly diluted in a carrier gas. Herein, therefore, we also explore the differences between the CVS (gas-phase) and solid-state transformation of a particular precursor in the formation of $\mathrm{Zn}_{2} \mathrm{SiO}_{4}$
A suitable organometallic precursor for the preparation of zinc silicate should possess sufficient volatility and contain all the necessary elements. In this study a siloxy-substituted tetranuclear heterocubane cluster (also denoted as "cubane" in the text) of the formula $\left[\left\{\mathrm{MeZnOSiMe}_{3}\right\}_{4}\right]$ is used. Although the siloxy-substituted zinc compounds have been known for a long time, ${ }^{[13]}$ no investigation, to the best of our knowledge, has so far been carried out on their use as a precursor for $\mathrm{Zn}_{2} \mathrm{SiO}_{4}$ synthesis. The precursor we use here, $\left[\left\{\mathrm{MeZnOSiMe}_{3}\right\}_{4}\right]$, has the advantages that it is easily accessible, even in gram amounts, ${ }^{[14]}$ and contains the elements $\mathrm{Zn}: \mathrm{Si}(: \mathrm{O})$ in the ratio 1:1(:1). Thus, formation of zinc silicate is expected to be possible under oxidizing conditions.

\section{Results and Discussion}

We first investigate the solid-state transformation of the precursor and then describe the CVS synthesis.

\section{Investigation of the solid-state decomposition}

The solid-state transformation of the cubane to zinc silicate was mainly studied by thermogravimetric analysis (TGA). As found by powder X-ray diffraction (XRD), the precursor slowly decomposes to $\mathrm{ZnO}$ due to atmospheric humidity, when exposed to air. To obtain insight into the thermal decomposition of the precursor under both inert gas and oxidizing conditions, TGA, differential thermogravimetric analysis (DTG), and differential thermal analysis (DTA) were performed (Figure 1).

The precursor begins to lose weight at $60^{\circ} \mathrm{C}$ under an argon atmosphere (see Figure $1 \mathrm{a}$ ). A continuous but slow loss $(5 \%)$ in mass occurs up to $180^{\circ} \mathrm{C}$, which we attribute to the sublimation of the cubane. For the CVS experiments that are discussed later, it is important to confirm that the cubane enters the gas phase in tact. We therefore studied the vapor composition resulting from heating the cubane in a separate experiment. The cubane was heated from 60 to $140^{\circ} \mathrm{C}$ over $72 \mathrm{~h}$ in the evaporation furnace of the CVS equipment (Figure 2), passed through the second furnace (at $300^{\circ} \mathrm{C}$ ), and the solid products collected (everything under inert-gas conditions). ${ }^{[14 \mathrm{~b}]}$ The XRD pattern of this deposit was recorded and compared to the pure cubane reference. Practically identical patterns (not shown) are obtained. Additionally, the NMR spectrum of the deposit (taken in $\mathrm{C}_{6} \mathrm{D}_{6}$ $\left.\delta_{\mathrm{ZnMe}}=0.01 \mathrm{ppm} ; \delta_{\mathrm{OSiMe} 3}=0.4 \mathrm{ppm}\right)$ shows nondecomposed cubane. Additionally, traces of by-products $(\approx 2-4 \%)$ were detected by NMR spectroscopy. The chemical shifts of the latter have been assigned to polysiloxane species. We conclude that the cubane undergoes negligible decomposition, even up to $300^{\circ} \mathrm{C}$ in the gas phase, in an inert atmosphere. This is in contrast to the behavior of the cubane during solid-state decomposition, as further investigated by TGA (discussed later). The composition of the cubane vapor was further investigated by TGA-MS to improve the understanding of the solid-state decomposition of the cubane. However, the extended description of these results is beyond the scope of this paper, and is given elsewhere. ${ }^{[15]}$ 


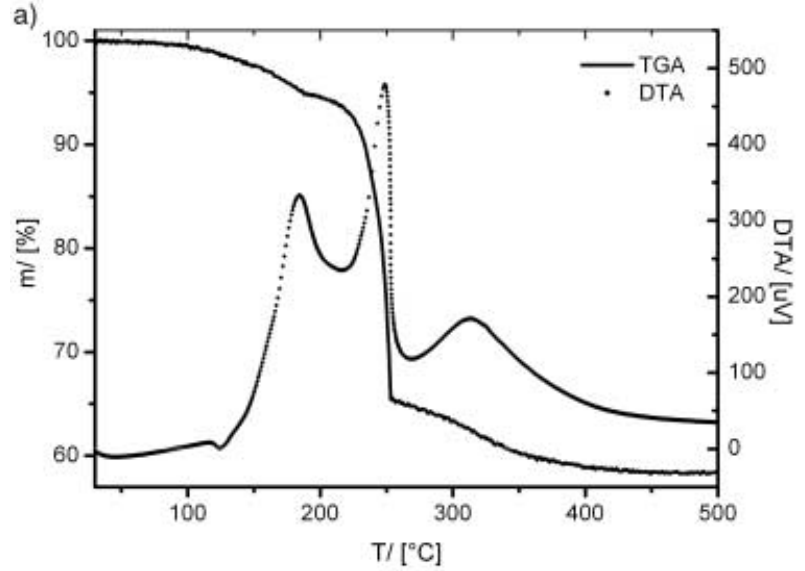

b)

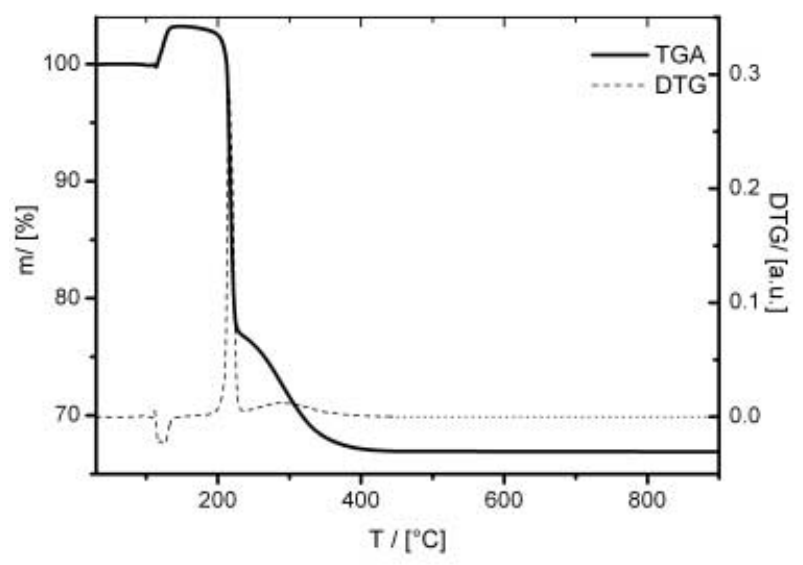

c)

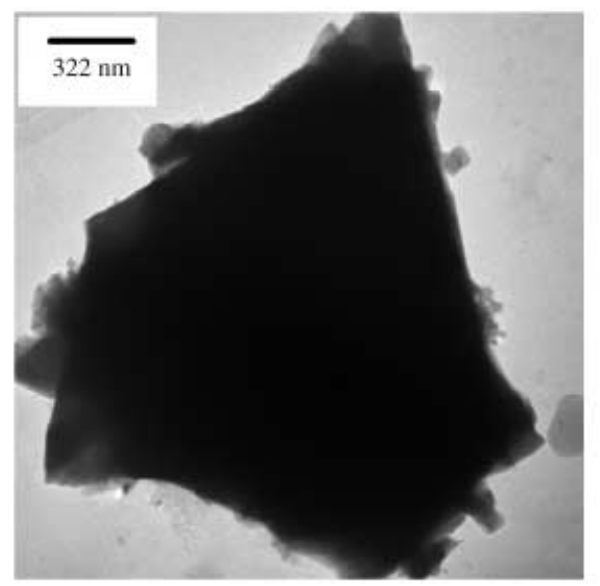

Figure 1. Thermogravimetric analysis (TGA) traces showing the decomposition of the cubane in an inert atmosphere (a) and in an oxygen-containing atmosphere (b). DTA = differential thermochemical analysis, DTG $=$ differential thermogravimetry. c) TEM image of the particles resulting from the solid-state decomposition of the cubane in air at a temperature of $900^{\circ} \mathrm{C}$.

From that study we note that sublimation of the cubane leads to a vapor that contains mostly intact cubane (> $90 \%$ ), but also small amounts of gaseous decomposition products such as $\mathrm{Me}_{4} \mathrm{Si}$.
To understand the differences between solid-state and gas-phase scenarios, it is necessary to examine the solidstate decomposition process more carefully.

The solid-state decomposition, studied by TGA, takes place in the region between 184 and $270{ }^{\circ} \mathrm{C}$ (see Figure $1 \mathrm{a}$ ), and finally $\approx 58 \%$ mass is left over (mass loss $42 \%$ ). The previous results underline the difference between the gasphase and solid-state decomposition of this particular compound. The cubane $\left[\left\{\mathrm{MeZnOSiMe}_{3}\right\}_{4}\right]$ seems to be significantly less stable in the solid state than under CVS conditions $\left(T_{\text {decomp }}(\right.$ gas $) \gg T_{\text {decomp }}($ solid $\left.)\right)$. In previous studies this solid-state decomposition in an inert atmosphere was investigated in more detail. ${ }^{[15 b]}$ It was seen that the cubane undergoes two alternative decomposition pathways, one leading to $\mathrm{Zn}$ ( $+\mathrm{MeOSiMe}_{3}+$ polysiloxanes), and another to $\mathrm{ZnO}$ $\left(+\mathrm{Me}_{4} \mathrm{Si}\right)$.

However, in the case of a quantitative transformation of the cubane to $\mathrm{ZnO}$, the expected weight loss is $52 \%$ (in the case of the transformation to $\mathrm{Zn}$ and $\mathrm{MeOSiMe}_{3}$, the expected weight loss is even greater; $62 \%$ ). In addition to the $5 \%$, which had already been sublimated, some cubane evaporates between 200 and $270{ }^{\circ} \mathrm{C}$ without decomposition. The behavior of the cubane can be investigated in more detail by DTA measurements (Figure $1 \mathrm{a}$ ), and at low temperature we find a negative DTA signal, which we attribute to the sublimation of the cubane. The first strong exothermic process is found in the temperature region $140-185^{\circ} \mathrm{C}$, where a maximum is reached. However, the main decomposition process takes place at higher temperatures, with a maximum at $248^{\circ} \mathrm{C}$. A third DTA maximum occurs at $312^{\circ} \mathrm{C}$, with significant heat being released, although the mass loss is relatively small. As was mentioned before, possible products of the decomposition under argon are $\mathrm{Zn}$ or $\mathrm{ZnO}$ as described elsewhere. ${ }^{[15]}$

We then decided to study the influence of oxygen addition upon the solid-state decomposition, as CVS is also conducted in an oxygen-containing atmosphere. The TGA trace $\left(5 \mathrm{~K} \mathrm{~min}^{-1}\right.$ heating rate) is shown in Figure $1 \mathrm{~b}$. By comparing Figure $1 \mathrm{a}$ and $\mathrm{b}$ it becomes evident that oxygen has significant impact on the decomposition behavior of the cubane. There is practically no mass change in the temperature region between 25 and $113^{\circ} \mathrm{C}$. Then, surprisingly, the mass increases by $3.2 \%$. We attribute this to oxidation of the cubane. The mass is practically constant until $200^{\circ} \mathrm{C}$. The decomposition of the cubane then occurs almost instantaneously. This can be clearly seen in the DTG curve which shows that the mass-loss signal is very narrow with a maximum at $216^{\circ} \mathrm{C}$. There is a subsequent slower loss of mass of $10 \%$ between 225 and $440{ }^{\circ} \mathrm{C}$. Finally, at $900^{\circ} \mathrm{C}, 66.9 \%$ of the initial mass is left. In the case of a quantitative transformation of the cubane to $\mathrm{Zn}_{2} \mathrm{SiO}_{4}\left(+\mathrm{SiO}_{2}\right)$, the expected residue would be $69.3 \%$. The lower actual yield can be explained by sublimation of the cubane. It should also be noted that a brownish-black powder was obtained, which still contained around $3 \%$ of carbon. The XRD analysis of this material (Figure $3 \mathrm{e}$ ) showed that $\alpha-\mathrm{Zn}_{2} \mathrm{SiO}_{4}$ is the main product of the solid-state decomposition of the cubane when an oxygen-containing atmosphere is used. All diffraction peaks, except for the one at $2 \theta=36.3^{\circ}$, can be correlat- 


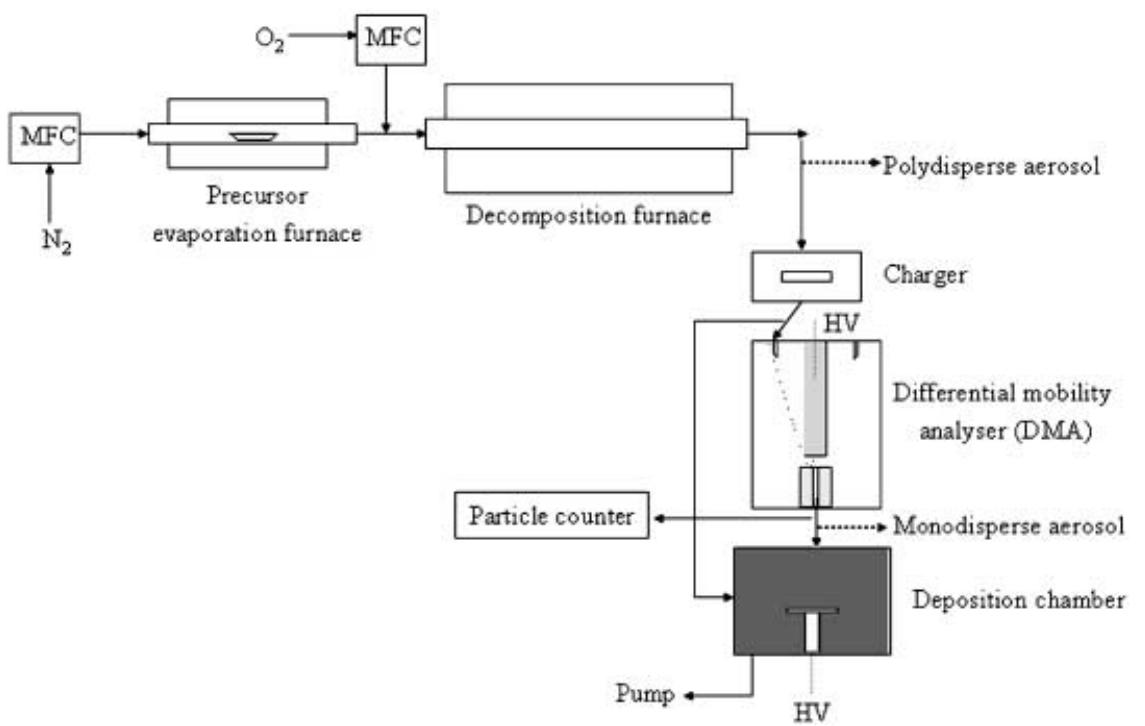

Figure 2. Experimental setup for the CVS decomposition of the cubane to $\mathrm{Zn}_{2} \mathrm{SiO}_{4}$. the determination of the particle size from PXRD data by using the Scherrer equation is reliable only for particles below $50 \mathrm{~nm}$, because measurementspecific effects always lead to line broadening, even when the particles are larger in reality. Thus, we also investigated the particles that resulted from the solid-state decomposition in an oxygen atmosphere at a final temperature of $900^{\circ} \mathrm{C}$ (Figure $1 \mathrm{c})$ by TEM. Huge particles, ranging from several hundred nanometers to micrometers, are found. Due to the limited transparency of these particles in the electron beam, it was not possible to establish whether these particles contain smaller particles with sizes similar to those calculated from PXRD.

Summarizing the results obtained for this section, we can say that evaporation of the cubane into the gas phase is feasible without decomposition at temperatures below $300^{\circ} \mathrm{C}$. At temperatures below $160^{\circ} \mathrm{C}$ (in argon) there is also minimal solid-state decomposition of the cubane in the evaporation boat, which only results in a decrease of the evaporation rate. We therefore decided on a maximum temperature of $140{ }^{\circ} \mathrm{C}$ for the evaporation of the cubane. It is further seen that the transformation of the cubane to $\alpha-\mathrm{Zn}_{2} \mathrm{SiO}_{4}$ is indeed realized under oxidizing conditions. Thus, analogous transformations under CVS conditions will be studied in the next section. The previous findings, therefore, provide the motivation for the particular setup we used for the CVS experiments (Figure 2).

\section{Decomposition under CVS conditions}

The cubane was vaporized in flowing $\mathrm{N}_{2}$ in a tube furnace. $\mathrm{O}_{2}$ was then added to oxidize it inside the second furnace (see Experimental Section and Figure 2 for details). As mentioned earlier, the decomposition under CVS conditions is rather different from the solid-state decomposition, since the precursor concentration is only in the parts per million (ppm) range. For example, in the present study, the maximum precursor concentration was $\approx 4 \mathrm{ppm}$ (on a molar basis, measured by a gravimetric method). The details of the CVS conditions and further sintering of these deposits are given in Table 1 and the setup for the experiment is shown in Figure 2. The products were investigated by XRD, IR, Raman, UV/VIS, and NMR spectroscopy, (HR)TEM, and elemental analysis.

XRD results: The XRD pattern of the product obtained by decomposing the cubane in presence of $\mathrm{O}_{2}$ at $750^{\circ} \mathrm{C}(\mathrm{Z750}$; see Table 1 ) is shown in Figure $3 \mathrm{a}$. The absence of diffraction peaks indicates that the deposited material is amorphous. The deposit was further heated to $750^{\circ} \mathrm{C}$ in a pure 
Table 1. Experimental conditions.

\begin{tabular}{llllll}
\hline Sample code & Precursor temperature $\left[{ }^{\circ} \mathrm{C}\right]$ & $\begin{array}{r}\text { Decomposition conditions (aerosol in } \\
33 \% \mathrm{O}_{2}+67 \% \mathrm{~N}_{2} \text { ) }\end{array}$ & $\begin{array}{c}\text { Sintering conditions (as } \\
\text { powder in pure argon) }\end{array}$ \\
\hline & & temperature $\left[{ }^{\circ} \mathrm{C}\right]$ & residence time $[\mathrm{s}]$ & temperature $\left[{ }^{\circ} \mathrm{C}\right]$ & time $[\mathrm{h}]$ \\
Z750 & $60-140$ & 750 & 13 & - & - \\
Z750S & $60-140$ & 750 & 13 & 750 & 4 \\
Z900 & $60-140$ & 900 & 11 & - & - \\
Z900S & $60-140$ & 900 & 11 & 900 & 2 \\
\hline
\end{tabular}

$\mathrm{Zn}_{2} \mathrm{SiO}_{4}$ on further sintering of these particles in an inert atmosphere suggests that $\beta$ $\mathrm{Zn}_{2} \mathrm{SiO}_{4}$, and $\mathrm{Zn}_{1.7} \mathrm{SiO}_{4}$ are homogeneously distributed. The crystallite size of $\alpha-\mathrm{Zn}_{2} \mathrm{SiO}_{4}$ prepared by post sintering was calculated from the full width at half maximum (FWHM) of the $(220)$ peak $\left(2 \theta=25.56^{\circ}\right)$

argon atmosphere for four hours to give the Z750S sample. The XRD pattern of this compound shows the presence of several broad peaks (Figure $3 \mathrm{~b}$ ). Most of these peaks can be assigned to $\beta-\mathrm{Zn}_{2} \mathrm{SiO}_{4}$ (JCPDS: 14-0653) without any ambiguity. It should be noted that $\beta-\mathrm{Zn}_{2} \mathrm{SiO}_{4}$ is a metastable phase that occurs under certain process conditions, and is quite stable at room temperature. ${ }^{[16]}$ At high temperatures, however, this phase transforms into $\alpha-\mathrm{Zn}_{2} \mathrm{SiO}_{4} \cdot{ }^{[16]}$ The origin of the so-far unassigned peaks in the XRD pattern (Figure $3 \mathrm{~b}$ ) may either be $\mathrm{ZnO}$ (JCPDS: 36-1451) or $\mathrm{Zn}_{1.7} \mathrm{SiO}_{4}$ (JCPDS: 24-1466). Similar diffraction patterns have been reported by Kang et al. ${ }^{[10 b]}$ They assigned the mentioned diffraction peaks to $\mathrm{ZnO}$ present as an impurity in the sample. However, the peaks at $2 \theta=24.6^{\circ}$ and $26.8^{\circ}$ cannot be assigned to $\mathrm{ZnO}$. On the other hand, all the peaks in the present XRD pattern match very well when the peaks are attributed to $\beta-\mathrm{Zn}_{2} \mathrm{SiO}_{4}$ and $\mathrm{Zn}_{1.7} \mathrm{SiO}_{4}$. One should note that $\mathrm{Zn}_{1.7} \mathrm{SiO}_{4}$ is also a metastable phase that exists at high pressures (>80 kbar). ${ }^{[17]}$ Although the particle formation processes took place at 1 bar in the present study, the pressure inside the nanometer-sized particles will be significantly higher. The relationship between interior pressure and particle size is given by the Laplace-Young relationship. ${ }^{[18]}$ The Laplace-Young relationship demonstrates that the pressure inside nanosized particles is higher than the external pressure, and thus may stabilize a high-pressure phase. This phenomenon has been reported for other systems: for example, a high-pressure phase of alumina $\left(\gamma-\mathrm{Al}_{2} \mathrm{O}_{3}\right)$ was found when the size of alumina particles approached $\sim 35 \mathrm{~nm}$, and a high-pressure cubic phase was observed in $5 \mathrm{~nm} \mathrm{CdS}$ particles. ${ }^{[18 b, 19]}$ Therefore, it is possible to rationalize the formation of $\mathrm{Zn}_{1.7} \mathrm{SiO}_{4}$. Nevertheless, we applied HRTEM (see below) to confirm its occurrence.

The XRD pattern of the as-deposited sample Z900, obtained at a temperature of $900^{\circ} \mathrm{C}$ in the decomposition furnace, is shown in Figure $3 \mathrm{c}$. The XRD results are very similar to those obtained for the Z750S sample and show a mixture of $\beta-\mathrm{Zn}_{2} \mathrm{SiO}_{4}$ and $\mathrm{Zn}_{1.7} \mathrm{SiO}_{4}$. The XRD pattern of the samples sintered at $900^{\circ} \mathrm{C}(\mathrm{Z} 900 \mathrm{~S})$ shows (Figure $3 \mathrm{~d}$ ) that the heat treatment induces a phase transition to $\alpha-\mathrm{Zn}_{2} \mathrm{SiO}_{4}$ (JCPDS: 37-1485). One may expect the formation of $\mathrm{SiO}_{2}$ due to the presence of an equal atomic ratio of zinc and silicon in the starting precursor. However, no diffraction peaks of $\mathrm{SiO}_{2}$ were observed at this temperature, since $\mathrm{SiO}_{2}$ is amorphous at this temperature. The presence of $\beta-\mathrm{Zn}_{2} \mathrm{SiO}_{4}$ and $\mathrm{Zn}_{1.7} \mathrm{SiO}_{4}$ in the as-prepared sample at $900^{\circ} \mathrm{C}$ is due to the very short residence time of the particles inside the hot zone of the furnace $(11 \mathrm{~s})$, which is probably not sufficient for the $\alpha-\mathrm{Zn}_{2} \mathrm{SiO}_{4}$ to be formed directly. The formation of $\alpha$ - using Scherrer's equation, and gave $d_{c}=39 \mathrm{~nm}$. This result clearly indicates the formation of nanocrystalline $\alpha-\mathrm{Zn}_{2} \mathrm{SiO}_{4}$ with the smallest crystallite size reported so far. Shortening of the heat treatment will probably reduce the crystal growth and hence cause a further decrease in crystallite size.

Thus, CVS enabled the transformation of the cubane $\left[\left\{\mathrm{MeZnOSiMe}_{3}\right\}_{4}\right]$ into $\alpha-\mathrm{Zn}_{2} \mathrm{SiO}_{4}$ in several steps. It seems that at first an amorphous phase containing $\mathrm{Zn}, \mathrm{Si}$, and $\mathrm{O}$ is formed, which we denote as $(\mathrm{Zn}-\mathrm{O}-\mathrm{Si})_{n}$. At higher temperatures or on longer heat treatment (Z750S and Z900), a metastable zinc-silicate phase results, which can finally be transformed into $\alpha-\mathrm{Zn}_{2} \mathrm{SiO}_{4}$. An open question that remains after XRD analysis is whether zinc silicate is the only product or whether other noncrystalline phases exist.

FT-IR results: To monitor the transformation from the cubane to $\alpha-\mathrm{Zn}_{2} \mathrm{SiO}_{4}$, we recorded FT-IR spectra of the different stages prepared by the CVS method (Figure 4). The IR spectra of the cubane, nanocrystalline $\mathrm{ZnO}$ (crystallite size $\sim 50 \mathrm{~nm}$ ), and amorphous $\mathrm{SiO}_{2}$ serve as reference spectra. Only the region between 1300 and $400 \mathrm{~cm}^{-1}$ is shown because the main vibrational modes of the orthosilicates fall

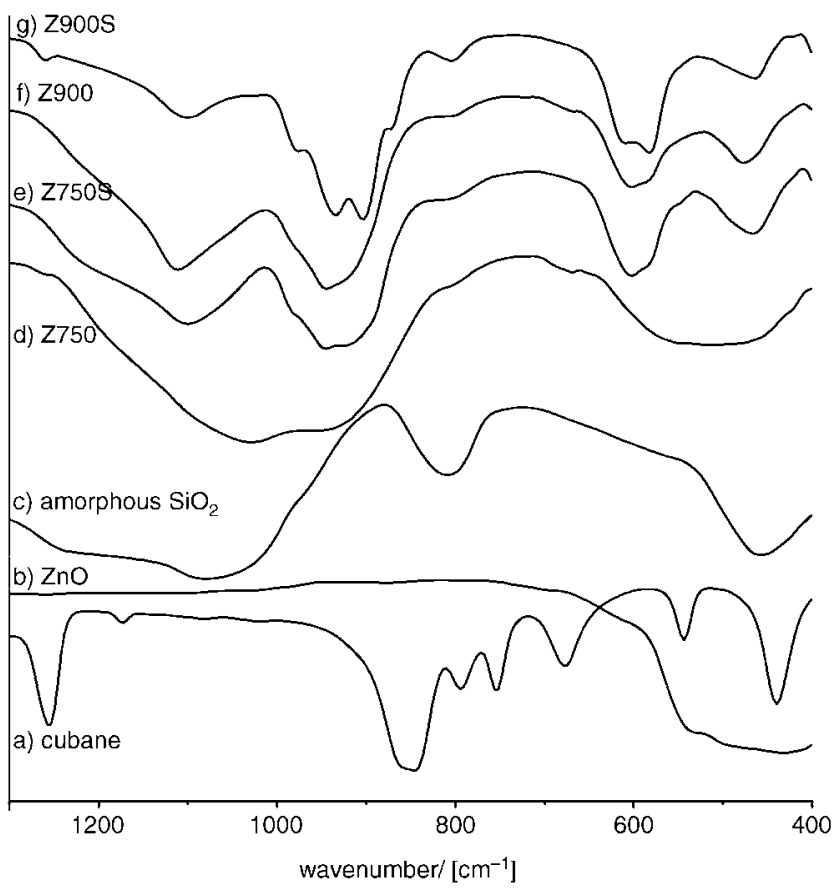

Figure 4. FT-IR spectra of a) starting precursor $\left[\left\{\mathrm{MeZnOSiMe}_{3}\right\}_{4}\right]$, b) nanocrystalline $\mathrm{ZnO}$, c) pure $\mathrm{SiO}_{2}$, d) Z750, e) Z750S, f) Z900, and g) Z900S. 
into this range. The spectrum of the Z750 sample shows the presence of two broad absorption bands with the minima at $\approx 1000$ and $500 \mathrm{~cm}^{-1}$ (Figure $4 \mathrm{~d}$ ). This spectrum is different from that of the starting precursor (Figure $4 \mathrm{a}$ ) and is very similar to the reported results for the amorphous gel produced in the sol-gel synthesis of $\mathrm{Zn}_{2} \mathrm{SiO}_{4}{ }^{[\mathrm{[a}, \mathrm{b}]}$ However, to fully understand the IR spectrum of $\mathrm{Z750}$, it is worthwhile to consider the spectra of $\mathrm{ZnO}$ and amorphous $\mathrm{SiO}_{2}$ in some detail (see Figure $4 \mathrm{~b}$ and c). Amorphous silica (Figure $4 \mathrm{c}$ ) has three intense bands at 1080,807 , and $452 \mathrm{~cm}^{-1}$, and one less-intense band at $1235 \mathrm{~cm}^{-1}$. Pure nanocrystalline $\mathrm{ZnO}$ has a band at $430 \mathrm{~cm}^{-1}$. It seems that the spectrum of Z750 is a superposition of the IR spectra of silica and zinc oxide. This also explains why the bands appear so broad. IR spectroscopy is a valuable technique because it provides clues for certain bonding motifs. Thus, the Z750 sample definitely contains $\mathrm{Si}-\mathrm{O}-\mathrm{Si}$ and $\mathrm{Zn}-\mathrm{O}-\mathrm{Zn}$ bonds (as in $\mathrm{ZnO}$ ). However, the strong bands at 940 and $546 \mathrm{~cm}^{-1}$ (not resolved) in the $\mathrm{Z} 750$ sample cannot be assigned to $\mathrm{Si}-\mathrm{O}$ or $\mathrm{Zn}-\mathrm{O}$ stretching modes, respectively. ${ }^{[\mathrm{[a}, 20]}$ These bands have to be assigned to a new feature. The IR spectrum of the Z900S sample (see Figure $4 \mathrm{~g}$ ), for which it is already known that zinc silicate is the main component, helps to understand these two bands, because the main bands of the Z900S sample are in the same frequency region. Therefore, we interpret these two bands as an indication of the occurrence of $\mathrm{Zn}-\mathrm{O}$-Si bonds, similar to those present in zinc silicates. The amorphous character of the Z750 sample explains why the bands representing the $\mathrm{Zn}-\mathrm{O}-\mathrm{Si}$ bonds are so broad and unresolved.

The observed vibrational modes for the Z900S samples occur at 1100, 975, 935, 903, 870, 800, 610, 580, and $460 \mathrm{~cm}^{-1}$ (Figure $4 \mathrm{e}$ ), with the bands relatively well-defined. The absorption modes at 975, 935, 903, 870, 610, 580, and $460 \mathrm{~cm}^{-1}$ are due to $\mathrm{Zn}_{2} \mathrm{SiO}_{4}$, and the position of the absorption bands is very similar to the reported IR spectrum of bulk $\mathrm{Zn}_{2} \mathrm{SiO}_{4}{ }^{[6 a, 20]}$ The absorption bands at 1100 and $800 \mathrm{~cm}^{-1}$ match well with the reported data for $\mathrm{SiO}_{2}$, and thus can be clearly assigned to amorphous $\mathrm{SiO}_{2}$ present within the sample. ${ }^{[20]}$ The IR spectra of the samples Z750S and Z900 were recorded as well. As already seen by XRD, these two samples do not differ much. The very broad and unstructured bands that occurred for the amorphous and ill-defined $(\mathrm{Zn}-\mathrm{O}-\mathrm{Si})_{n}$ phase of the $\mathrm{Z} 750$ sample are replaced by much more structured bands. The typical modes for $\mathrm{Zn}_{2} \mathrm{SiO}_{4}$ $\left(932 \mathrm{~cm}^{-1}\right), \mathrm{Si}-\mathrm{O}\left(1098 \mathrm{~cm}^{-1}\right)$, and $\mathrm{Zn}-\mathrm{O}\left(466 \mathrm{~cm}^{-1}\right)$ can be clearly identified in the Z750S and Z900 samples. The bands of the Z900 sample even appear a bit more defined than those of the Z750S sample, but not as structured as for the Z900S sample. It is also very interesting to compare the transition $\mathrm{Z} 900 \rightarrow \mathrm{Z} 900 \mathrm{~S}$ (Figure $4 \mathrm{f}$ and $\mathrm{g}$ ). The characteristic bands for $\mathrm{Zn}_{2} \mathrm{SiO}_{4}$ become more defined, but at the same time the bands for $\mathrm{Si}-\mathrm{O}$ and $\mathrm{Zn}-\mathrm{O}$ decrease, which indicates that the $\mathrm{Si}-\mathrm{O}$ and $\mathrm{Zn}-\mathrm{O}$ bonds are broken during the conversion to $\mathrm{Zn}_{2} \mathrm{SiO}_{4}$.

The intensity of the bands for the $\mathrm{Si}-\mathrm{O}$ bonds in the IR spectra is very high; therefore, we decided to analyze the samples by Raman spectroscopy as well in an attempt to gain additional important information.
Raman results: The motivation for applying Raman spectroscopy was to confirm the presence of $\mathrm{ZnO}$ in the ZS750S and ZS900 samples. However, instead of getting a well-resolved Raman spectrum of $\mathrm{ZnO}$ as reported in the literatur$\mathrm{e},{ }^{[20 \mathrm{~b}]}$ we found spectra that were dominated by fluorescence radiation. This fluorescence radiation is, especially in the case of zinc silicate systems, typical for nanoscaled zinc silicate particles. Similar findings have been reported before. ${ }^{[20 c]}$

Solid-state NMR results: We probed the local chemical environment in this system by ${ }^{29} \mathrm{Si}-\mathrm{MAS}$ NMR spectroscopy, and recorded solid-state NMR spectra of the Z750, Z900, and Z900S samples (Figure 5); amorphous $\mathrm{SiO}_{2}$ was meas-

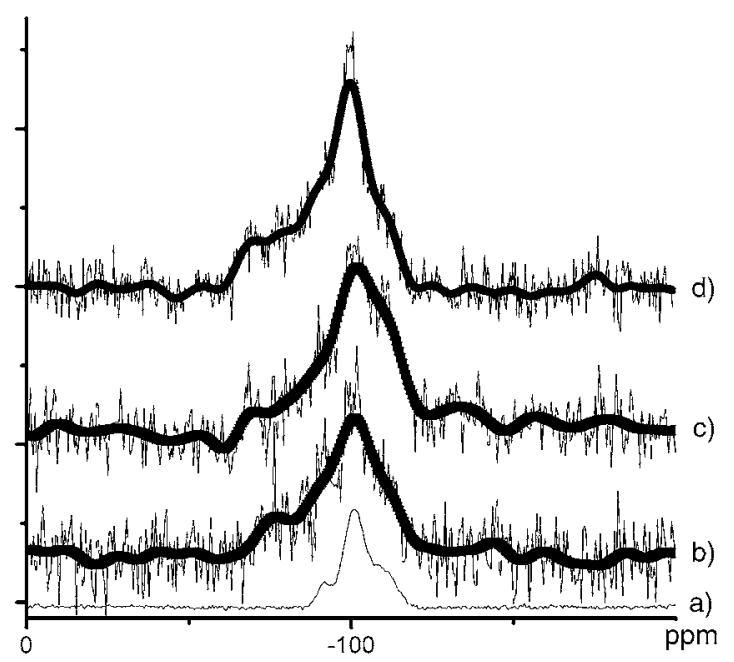

Figure 5. Solid-state (MAS) ${ }^{29} \mathrm{Si}-\mathrm{NMR}$ spectra of a) amorphous $\mathrm{SiO}_{2}$, b) Z750, c) Z900, and d) Z900S.

ured as a reference sample. As is typical for amorphous silica, a group of three ${ }^{29} \mathrm{Si}$ NMR signals $\left(q^{2}=-92, q^{3}=\right.$ $\left.-101, q^{4}=-110 \mathrm{ppm}\right)$ is visible in Figure $5 \mathrm{a}$. The $q^{2 / 3 / 4}$ signals are significant for $\mathrm{SiO}_{4}$ tetrahedra with different degrees of condensation (Si-O-Si). The signal-to-noise ratio for the measurements is not ideal, despite measurement times of $48 \mathrm{~h}$ per sample. However, one difference in comparison to the $\mathrm{SiO}_{2}$ reference is evident. An additional band around $-70 \mathrm{ppm}$ appears in the spectra $(\mathrm{b}-\mathrm{d})$, which we attribute to the occurrence of $\mathrm{Si}-\mathrm{O}-\mathrm{Zn}$ species. This interpretation is supported by a previous report, ${ }^{[20 \mathrm{~d}]}$ in which the appearance of zinc-silicate nanoclusters in $\mathrm{ZnO} / \mathrm{SiO}_{2}$ mixtures was also evidenced by an additional signal in the ${ }^{29} \mathrm{Si}$ NMR spectrum at approximately $-70 \mathrm{ppm}$. A difference in chemical shift from $\mathrm{Z} 750(\delta=-76 \mathrm{ppm})$ to $\mathrm{Z} 900(\delta=-70 \mathrm{ppm})$ can also be seen, but due to the low signal-to-noise ratio it is questionable whether this difference is significant. Due to the low quality of the data it was difficult to evaluate the spectra in a quantitative fashion. However, deconvolution of the curves indicates that the signals representing $\mathrm{Si}$ atoms in a $\mathrm{Si}-\mathrm{O}-\mathrm{Zn}$ environment increase in the series $\mathrm{Z750} \rightarrow \mathrm{Z} 900 \rightarrow$ Z900S. This agrees with the findings from the IR measurements, and is also consistent with the results already presented for XRD investigations. The presence of Si-O-Si and $\mathrm{Si}-\mathrm{O}-\mathrm{Zn}$ species is therefore confirmed. 
Since the solid-state decomposition led to a product containing significant amounts of elemental carbon, the optical properties of the materials originating from the CVS process are of special importance.

Solid-state UV/Vis spectroscopy: First of all, it is important to note that the materials obtained by CVS are colorless powders. Elemental analysis did not detect the presence of carbon, thus proving a carbon content below $1 \%$. UV/Vis spectra were recorded in reflection mode. Keeping potential applications of the materials presented in this study in mind, it is important to gather information about their optical properties. There is only a very weak absorption at $674 \mathrm{~nm}$ in the visible region. A strong UV absorption $\left(\lambda_{1 / 2}\right)$ is found at $372 \mathrm{~nm}$, which can be attributed to $\mathrm{Zn}_{2} \mathrm{SiO}_{4}$, but also to $\mathrm{ZnO} .^{[20 e]}$

Taking the XRD, IR, UV/Vis, Raman and NMR results into consideration, the composition of the final products and the course of the transformation can be summarized as follows. The cubane is first transformed under the influence of oxygen into an amorphous phase that shows bond characteristics of $\mathrm{Zn}-\mathrm{O}-\mathrm{Si}$ (pre-organized in the cubane itself) as in zinc silicate, $\mathrm{Zn}-\mathrm{O}-\mathrm{Zn}$ (also pre-organized in the cubane), and $\mathrm{Si}-\mathrm{O}-\mathrm{Si}$ as in amorphous silica. To obtain further information about the morphology of the resulting materials, we performed transmission electron microscopy.

TEM results: Figure $6 \mathrm{a}$ shows the CTEM (conventional TEM) image of the polydisperse aerosol formed at $750^{\circ} \mathrm{C}$ (Z750). The micrograph shows the formation of aggregates
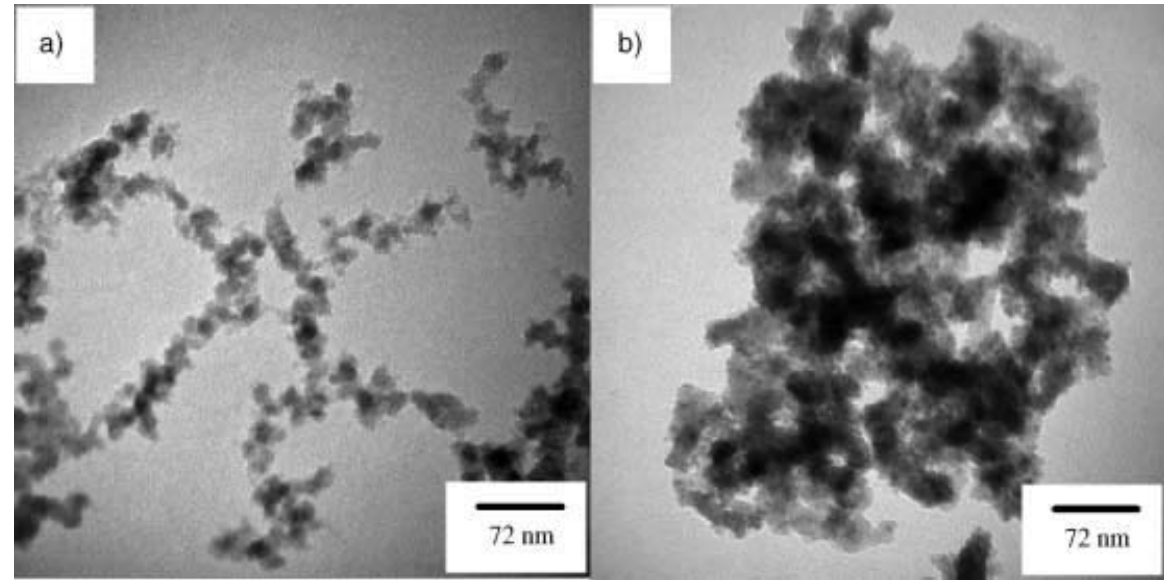

Figure 6. CTEM images of a) Z750 (bright field), b) Z750S (bright field)

containing several tens of primary particles with an average diameter of $12 \mathrm{~nm}$. The particles were found to be amorphous by electron diffraction, which is in agreement with XRD. Energy-dispersive X-ray (EDX) elemental analysis on twenty different aggregates confirms the homogeneous distribution of both $\mathrm{Zn}$ and $\mathrm{Si}$ in these particles. The $\mathrm{Zn}: \mathrm{Si}$ ratio was found to be almost 50:50 (within an error limit of $\pm 5 \%$ ). No individual agglomerate was found that contained either only $\mathrm{Zn}$ or $\mathrm{Si}$. These results indicate that the precursor in the gas phase directly oxidizes to give amorphous ma- terial without any dissociation of the $\mathrm{Zn}-\mathrm{O}-\mathrm{Si}$ motifs at this temperature. Thus, the CTEM results for the Z750 sample are in good agreement with the previously obtained XRD and IR results. The CTEM image of the Z750S sample (Figure $6 \mathrm{~b}$ ) shows the formation of large agglomerates, and the presence of a large amount of fine crystallites with a diameter of 5-8 $\mathrm{nm}$ inside the primary particles. These fine crystallites are probably the crystalline $\mathrm{Zn}_{1.7} \mathrm{SiO}_{4}$ or $\beta-\mathrm{Zn}_{2} \mathrm{SiO}_{4}$ phases as found by XRD.

The CTEM image of the aerosol formed at $900{ }^{\circ} \mathrm{C}(\mathrm{Z} 900)$ is shown in Figure $7 \mathrm{a}$. Interestingly, in contrast to the findings of the previously employed analytical methods, the Z750S and Z900 samples differ significantly. The micrograph shows that most of the particles formed at $900^{\circ} \mathrm{C}$ have a spherical morphology, are not agglomerated, and the particle diameter varies from 30 to $80 \mathrm{~nm}$. Looking at these spherical particles more closely at higher magnification reveals that some very small crystallites are embedded inside the matrix of the larger amorphous spherical particles. Figure $7 \mathrm{~b}$ shows the dark-field CTEM image of size-classified particles with a mobility-equivalent diameter of about $35 \mathrm{~nm}$ formed at $900^{\circ} \mathrm{C}$. The micrograph shows the presence of very fine crystallites $(3-5 \mathrm{~nm}$ in size). The sample was found to be very sensitive to the electron beam. Longer exposure of the spherically shaped particles gave rise to a roughening of the surfaces of these spheres, originating from a growth of the crystallites within the particles (even with a widely spread beam and reduced beam intensity).

To get a better insight into the composition of the fine 35-nm crystals, as well as into the amorphous matrix of the larger spheres $(30-80 \mathrm{~nm}$ in size), in which these fine crystals are embedded, high-resolution TEM (HRTEM) studies were performed on the Z900 sample. Figure $7 \mathrm{c}$ and $\mathrm{d}$ show two HRTEM images of sample Z900, which are slightly contrast-enhanced by the addition of a Fourier-filtered image to the original micrograph. The images clearly show the occurrence of small crystallites of roughly $5 \mathrm{~nm}$ in size. The measured lattice spacings are indicated in the figures. An unambiguous identification of the crystal phase from lattice spacings is hampered by the following facts. First, the error in the quantitative determination of the lattice spacings from a HRTEM image (that does not contain any lattice fringes usable for calibration) is as large as $3 \%$, and second, below $0.3 \mathrm{~nm}$, the lattice spacings $(d$ values) of all materials to be considered $\left(\mathrm{ZnO}, \mathrm{Zn}_{1.7} \mathrm{SiO}_{4}, \alpha-\right.$ $\mathrm{Zn}_{2} \mathrm{SiO}_{4}$ and $\beta-\mathrm{Zn}_{2} \mathrm{SiO}_{4}$ ) are very similar. However, according to the XRD results, the occurrence of $\alpha-\mathrm{Zn}_{2} \mathrm{SiO}_{4}$ can be ruled out. As a consequence, the observed lattice spacings of $d=0.248,0.278$, and $0.283 \mathrm{~nm}$ confirm the presence of $\mathrm{ZnO}, \mathrm{Zn}_{1.7} \mathrm{SiO}_{4}$, or $\beta-\mathrm{Zn}_{2} \mathrm{SiO}_{4}$ nanocrystals. Within the error 

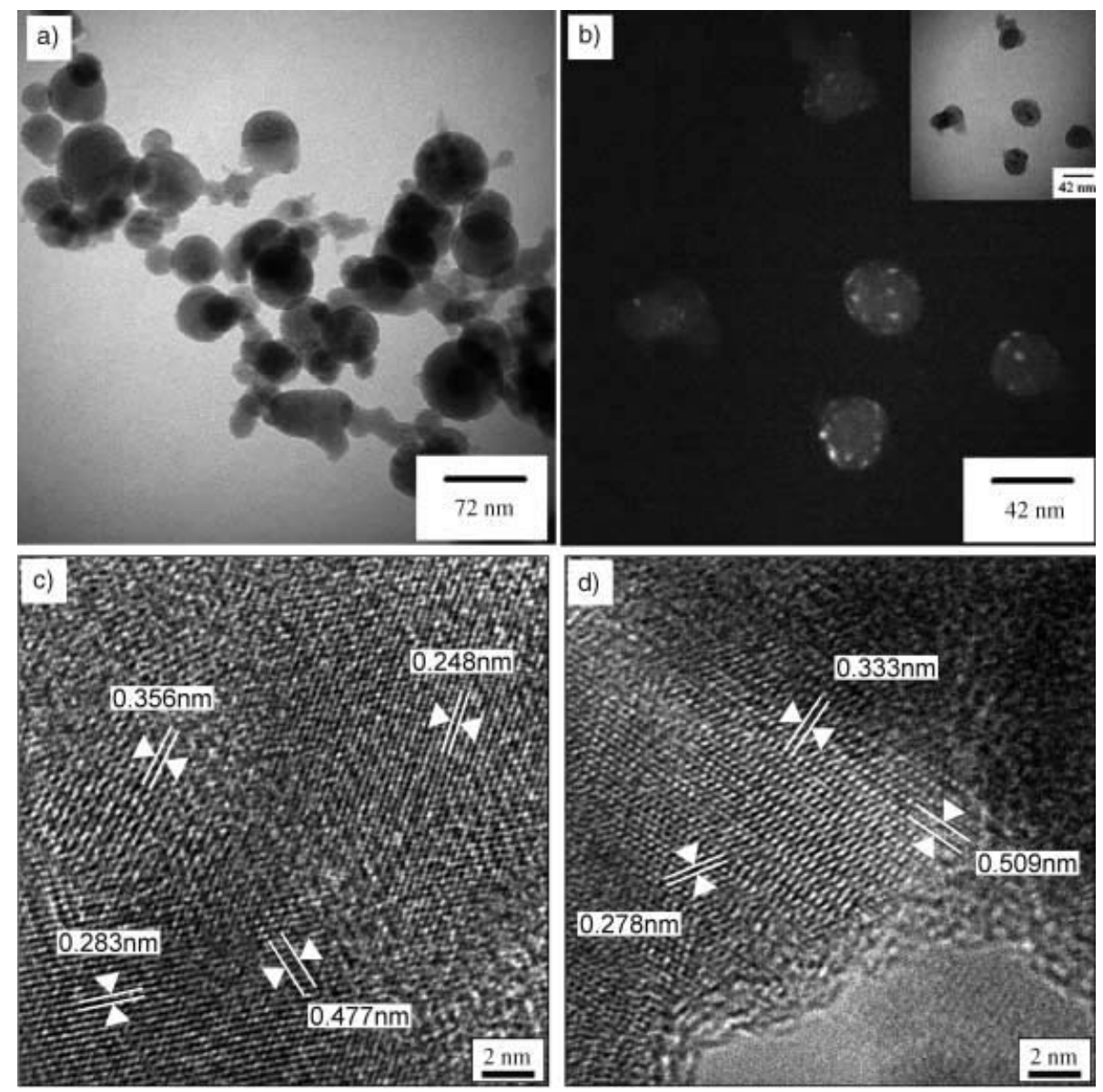

Figure 7. a) Bright-field CTEM image of Z900, b) dark-field CTEM image of size-classified particles of $35 \mathrm{~nm}$ produced under the conditions of sample Z900 ( $\mathrm{tilt}=0.8 \mathrm{~d}$ ). Inset: corresponding bright field image, c) and d) HRTEM image of Z900

limits, the lattice spacing of $d=0.356 \mathrm{~nm}$ may be attributed to either $\mathrm{Zn}_{1.7} \mathrm{SiO}_{4}$ or $\beta-\mathrm{Zn}_{2} \mathrm{SiO}_{4}$. The observed values of $d=0.333,0.477$, and $0.509 \mathrm{~nm}$ only occur in $\mathrm{Zn}_{17} \mathrm{SiO}_{4}$ nanocrystals. Line-scan EDX and electron energy loss spectroscopy (EELS) on the spherical particles also show the presence of $\mathrm{Zn}, \mathrm{Si}$, and $\mathrm{O}$ in the amorphous matrix. The HRTEM results together with the XRD and IR results on the Z900 sample lead us to conclude that these fine crystallites are $\mathrm{Zn}_{1.7} \mathrm{SiO}_{4}$ or $\beta-\mathrm{Zn}_{2} \mathrm{SiO}_{4}$. Bearing in mind the overall 1:1 atomic composition of $\mathrm{Zn}: \mathrm{Si}$ (from EDX) in the large spherical particles, the presence of fine crystallites of $\mathrm{Zn}_{1.7} \mathrm{SiO}_{4}$ or $\beta-\mathrm{Zn}_{2} \mathrm{SiO}_{4}$ inside these spherical particles, and the presence of both $\mathrm{Zn}$ and $\mathrm{Si}$ in the amorphous matrix, leads to the conclusion that the amorphous matrix is rich in silicon.

The TEM image of the Z900S is shown in Figure 8a. The image shows that sintering induces neck formation between the primary particles and a more crystalline structure. The mean primary particle diameter was found to be about $42 \mathrm{~nm}$, which is close to the crystallite size obtained by $\operatorname{XRD}\left(d_{\mathrm{c}}=39 \mathrm{~nm}\right)$. This result might be taken to infer that the primary particles are mainly single-crystalline; however, dark-field CTEM analysis reveals the presence of very large numbers of 5-20-nm crystallites embedded inside an amorphous matrix (Figure 8b). The EDX analysis shows the presence of equal atomic percentages of $\mathrm{Zn}$ and $\mathrm{Si}$ in this sample. These results lead us to believe that fine crystallites of $\alpha-\mathrm{Zn}_{2} \mathrm{SiO}_{4}$ are embedded in an amorphous matrix of $\mathrm{SiO}_{2}$, which is in good agreement with XRD, MASNMR, and IR results.

The particle formation mechanism: The various analytical techniques provided us with sufficient information on the chemical and structural phase transformations. This allows us to propose a particle formation mechanism, which is shown in Figure 9. The subsequent steps will now be rationalized in detail.

A mixture of the gaseous cubane $\left[\left\{\mathrm{MeZnOSiMe}_{3}\right\}_{4}\right]$ and $\mathrm{O}_{2}$ enters the decomposition furnace. The temperature increases in the beginning of the hot zone and conversion into an unknown oxidized form of the cubane takes place. This is 


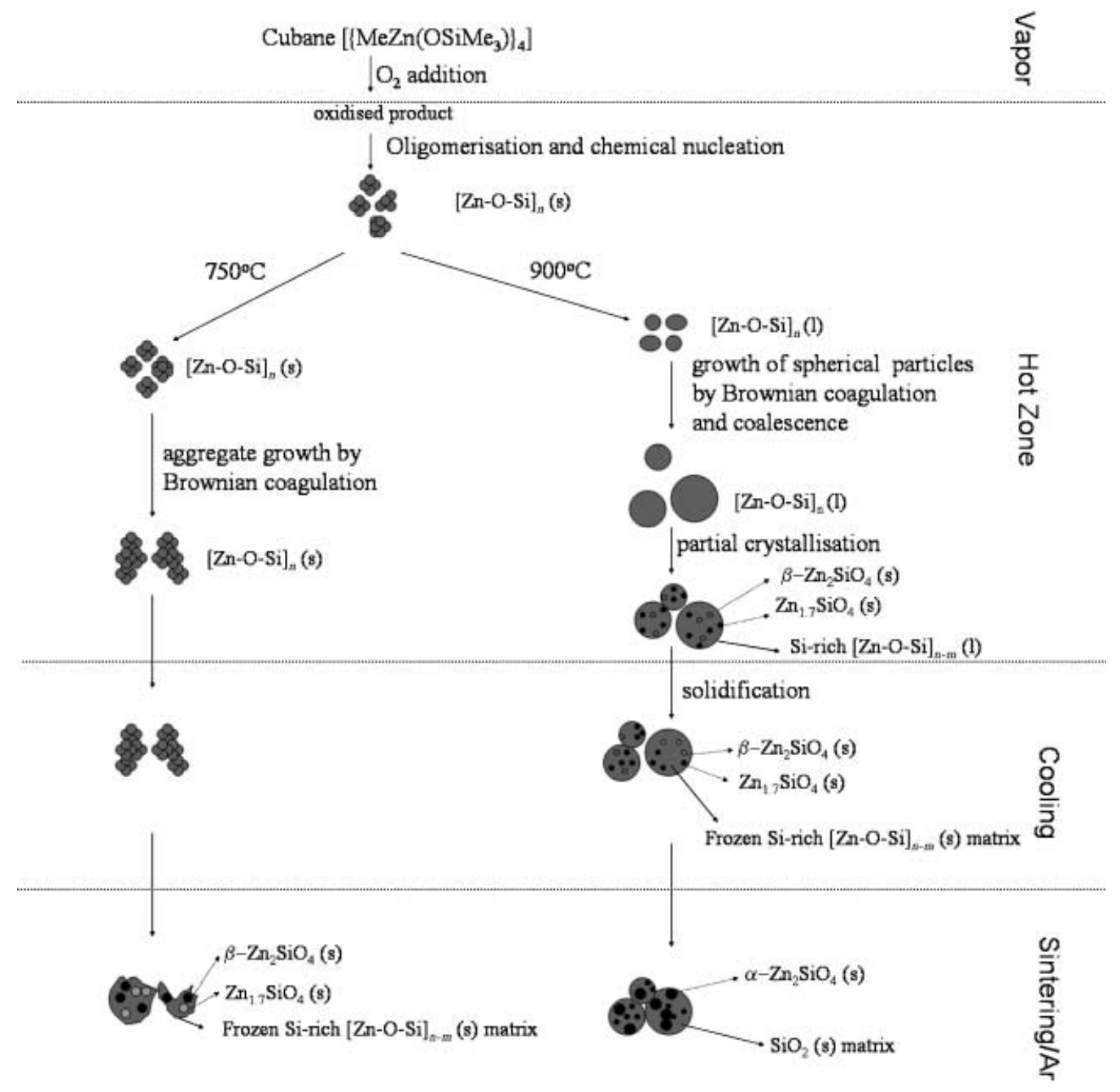

Figure 9. Proposed particle formation mechanism.

supported by the DTG results (see Figure $1 \mathrm{~b}$ ). In the hot zone of the decomposition furnace, particle formation is induced by oligomerization into $(\mathrm{Zn}-\mathrm{O}-\mathrm{Si})_{n}$ species, and, at the same time, breaking of the $\mathrm{Si}-\mathrm{C}$ bonds. The $\mathrm{Si}-\mathrm{O}$ motifs resulting from this oxidation are also suitable candidates for $\mathrm{Si}-\mathrm{O}-\mathrm{Si}$ formation. The oligomerization, which requires binary collisions, is limited due to the low concentration of the reactive gas-phase species $(\approx 4 \mathrm{ppm})$. Based on elementary kinetic gas theory and a collisional diameter of $0.86 \mathrm{~nm}$, we estimate that each cubane cluster experiences some $10^{5}$ collisions per second with other cubanes. Collisions will lead to an increase in the degree of aggregation of the ( $\mathrm{Zn}-\mathrm{O}-\mathrm{Si})_{n}$ phase. The increasing mass of these aggregates will lead to a rapid decrease in their vapor pressure $p_{s}$. Consequently, supersaturation $S=p / p_{S}$ increases until some critical value is exceeded, and the clusters become stable nuclei which then grow further.

After the cubane has been transformed into stable clusters, collisions between particles take place due to Brownian motion. Based on free molecular theory, we calculated the Brownian collision rate for the case where $4 \mathrm{ppm}$ (molar base) cubane was completely converted into $10 \mathrm{~nm}$ particles. Under these conditions, each particle experiences several hundred collisions per second, confirming that Brownian collisions play an important role. The appearance of spherical particles at $900^{\circ} \mathrm{C}$, in contrast to the aggregates at $750^{\circ} \mathrm{C}$, indicates that the $(\mathrm{Zn}-\mathrm{O}-\mathrm{Si})_{n}$ phase formed is liquid at $900^{\circ} \mathrm{C}$ and solid at $750^{\circ} \mathrm{C}$. Thus, at $900^{\circ} \mathrm{C}$, Brownian collisions of two liquid particles lead to the formation of one larger liquid particle (Figure $7 \mathrm{a}$ ). At $750^{\circ} \mathrm{C}$, solid particles collide and stick together due to van der Waals forces, leading to the formation of aggregates of small primary particles (Figure 6a).

Extended heat treatment at $750^{\circ} \mathrm{C}$, or an increase in decomposition temperature to $900^{\circ} \mathrm{C}$, leads to the formation of crystallites of $\beta-\mathrm{Zn}_{2} \mathrm{SiO}_{4}$ and $\mathrm{Zn}_{1.7} \mathrm{SiO}_{4}$ dispersed in a Sirich amorphous matrix.

Interestingly, in order to form zinc orthosilicate, a transition from the $(\mathrm{Zn}-\mathrm{O}-\mathrm{Si})_{n}$ phase to an ionic phase $\mathrm{Zn}_{2} \mathrm{SiO}_{4},{ }^{[20 a, 22]}$ containing $\mathrm{Zn}^{2+}$ and $\left[\mathrm{SiO}_{4}{ }^{4-}\right]$ ions, should take place. The formation of zinc silicate is expected to be exothermic, ${ }^{[23]}$ but the thermal energy at $900^{\circ} \mathrm{C}$ apparently only suffices to overcome the activation energy necessary to break the $\mathrm{Zn}-\mathrm{O}-\mathrm{Si}$ bonds. However, the residence time inside the furnace at $900^{\circ} \mathrm{C}$ is not sufficient to convert all the $(\mathrm{Zn}-\mathrm{O}-\mathrm{Si})_{n}$ phase into zinc silicate. Sintering the sample 
at $900^{\circ} \mathrm{C}$ increases the yield of zinc orthosilicate. The solidification of the Si-rich liquid phase occurred after the aerosol was cooled down and thus hindered further crystal growth by diffusion. The high cooling rate of several hundred degrees per second is probably responsible for the formation of metastable $\beta-\mathrm{Zn}_{2} \mathrm{SiO}_{4}$ rather than thermodynamically stable $\alpha-\mathrm{Zn}_{2} \mathrm{SiO}_{4}$. Only the extended heat treatment of the powder at $900^{\circ} \mathrm{C}$ converted the metastable phases into the stable $\alpha-\mathrm{Zn}_{2} \mathrm{SiO}_{4}$.

\section{Conclusion}

In the current contribution, a new method was introduced to prepare a material of immense technical interest, $\alpha$-willemite, in nanocrystalline form. It was shown that the cubane $\left[\left\{\mathrm{MeZn}\left(\mathrm{OSiMe}_{3}\right)\right\}_{4}\right]$ acts as a single-source precursor for $\alpha$ $\mathrm{Zn}_{2} \mathrm{SiO}_{4}$ under oxidizing conditions. Although solid-state decomposition of the cubane also gave $\alpha-\mathrm{Zn}_{2} \mathrm{SiO}_{4}$, the lack of nanocrystallinity and the occurrence of carbon contamination are disadvantageous. Thus, we studied the transformation of the cubane in the gas phase by chemical vapor synthesis. Surprisingly, the gas-phase decomposition of the cubane takes place at higher temperatures than the solidstate decomposition. The investigations showed that the $\mathrm{Zn}$ $\mathrm{O}-\mathrm{Si}$ bonds pre-organized in the cubane were retained in the final products. Interestingly, at low temperatures or short residence times, a metastable form $\left(\beta-\mathrm{Zn}_{2} \mathrm{SiO}_{4}\right)$ and a high-pressure phase $\left(\mathrm{Zn}_{1.7} \mathrm{SiO}_{4}\right)$ were formed. These phases transform into the desired $\alpha-\mathrm{Zn}_{2} \mathrm{SiO}_{4}$ imbedded in an amorphous $\mathrm{SiO}_{2}$ matrix through extended sintering at $900^{\circ} \mathrm{C}$. However, the smallest crystals of $\alpha-\mathrm{Zn}_{2} \mathrm{SiO}_{4}$ so far reported in the literature were still obtained. In contrast to the solidstate decomposition, the high dispersion of the species in the aerosol, and the improved contact with $\mathrm{O}_{2}$, led to a carbon-free product.

Chemical vapor synthesis and modern organometallic single-source precursor chemistry proves to be a very promising combination with which to obtain materials with a high degree of compositional control (purity of the materials) and morphological control (small particles).

In the future, we will extend our approach towards the synthesis of doped zinc-oxide-based materials by preparing suitable organometallic precursors.

\section{Experimental Section}

The volatile solid precursor used in this method was a siloxy-substituted tetranuclear heterocubane (cubane) and was synthesized by using the procedure reported earlier ${ }^{[14]}$ The precursor was handled under an inert atmosphere at all times using Schlenk-techniques and a glove box.

The experimental setup used for this study is depicted in Figure 2. It consists of an evaporation furnace, a decomposition furnace, a particle charger, a particle precipitator, and an on-line particle-size measurement system, which could also be used for size selections. The precursor was vaporized in a tube furnace at $60-140^{\circ} \mathrm{C}$ and then carried to another tube furnace using nitrogen as carrier gas. A flow rate of $1 \mathrm{~L} \mathrm{~min}^{-1}$ of $\mathrm{N}_{2}$ was used in the present study. For oxidation of the precursor, $0.5 \mathrm{~L} \mathrm{~min}^{-1}$ of $\mathrm{O}_{2}$ was added before the second furnace. Decomposition and oxidation of the precursor take place in the second furnace at elevated temper- atures. The particles formed after decomposition remain as an aerosol in the gas phase, and were then passed through a radioactive $\alpha$-source $\left({ }^{241} \mathrm{Am}\right)$ to charge the particles electrically. This polydisperse charged particles were then either deposited directly or passed through a differential mobility analyzer (DMA, TSI-Short, Minneapolis, USA) for size classification, and then deposited with $\approx 100 \%$ efficiency on a suitable substrate (TEM grid or Si (100) wafer) using an electrostatic precipitator. ${ }^{[24]}$ In the DMA the charged particles are size-selected on the basis of their electrical mobility, which is a function of their charge level, mass, and shape. Thus, choosing a particular applied voltage and flow ratio in the DMA, a monodisperse aerosol with an adjustable size between 10 and $100 \mathrm{~nm}$ and standard deviation below $10 \%$ can be obtained in the present system. A condensation nucleus counter (CNC, TSI, Model-3022, Minneapolis, USA) was used to monitor the aerosol number concentration. The produced polydisperse aerosol was then also examined with the differential mobility particle sizing (DMPS) technique (TSI, Model-3081) for particle size distribution with respect to time, precursor evaporation temperature, and precursor decomposition temperature. The deposited particles were scratched carefully from the substrate and then sintered further in a pure argon atmosphere.

$\mathrm{X}$-ray diffraction analyses of all the powder samples and deposited particles were performed on a Bruker - AXS D8 Advance using $\mathrm{Cu}_{\mathrm{K} \alpha}$ radiation and a position-sensitive detector (PSD). Thermogravimetric analyses (DTA-TG) of the precursor were carried out with a thermal analyzer (Seiko Instruments) in the range $25^{\circ} \mathrm{C}$ to $900^{\circ} \mathrm{C}$ in argon and oxygen. A linear rate of heating of $5 \mathrm{~K} \mathrm{~min}^{-1}$ was maintained during all the measurements. Conventional transmission electron microscopy (CTEM) was performed on a Philips CM12 microscope $\left(\mathrm{LaB}_{6}\right.$ filament, $120 \mathrm{kV}$, Twin lens) equipped with an energy-dispersive X-ray spectrometer (EDX, type Oxford Link). The sintered powder samples were suspended in cyclohexane using an ultrasonic bath for $5 \mathrm{~min}$ and then left to dry on a carboncoated TEM grid. High-resolution transmission electron microscopy (HRTEM) was conducted on a Philips Tecnai F20ST microscope (field emission gun, $200 \mathrm{kV}$, Super-Twin lens) equipped with an EDX system (type EDAX Phoenix) and a post-column Gatan image filter (type Gatan GIF 2000) for electron-energy loss spectroscopy. FT-IR spectra were recorded by using a Bruker Vector 22 spectrometer from KBr pellets. FTRaman spectra were recorded by using a Bruker IFS 66 spectrometer with a $532 \mathrm{~nm}$ excitation laser. UV/Vis spectra were recorded by using a Perkin Elmer Lambda 20 spectrometer equipped with a reflecting sphere Labsphere RSA-PE-20. Solid-state NMR spectra were recorded by using a Bruker DRX 400 spectrometer.

\section{Acknowledgement}

We thank the Deutsche Forschungsgemeinschaft (SPP 1119, CVS of nanocrystalline metal oxide and silicate films by pyrolysis of molecular metal alkoxides and metal siloxides) for financial support.

[1] a) K. G. Caulton, L. G. Hubert-Pfalzgraf, Chem. Rev. 1990, 90, 969995; b) C. D. Chandler, C Roger, M. J. Hampden-Smith, Chem. Rev. 1993, 93, 1205-1241; c) P. O'Brien, Precursors for Electronic Materials in Inorganic Materials (Eds.: D. W. Bruce, D. O'Hare), Wiley, New York, 1996, p. 525.

[2] a) K. H. Klaska, J. C. Eck, D. Pohl, Acta Crystallogr. Sect. B 1978, 34, 3324-3325. The term "phosphor material" is used throughout the text relating to materials possessing certain luminescence properties. It does not mean that the materials contain phosphorus.

[3] a) A. Morell, N. El. Khiati, J. Electrochem. Soc. 1993, 140, 20192022; b) C. Barthou, J. Benoit, P. Benalloul, A. Morell, J. Electrochem. Soc. 1994, 141, 524-528; c) T. Jüstel, H. Nikol, C. Ronda, Angew. Chem. 1998, 110, 3250-3271; Angew. Chem. Int. Ed. 1998, 37, 3084-3103; d) T. Jüstel, H. Nikol, Adv. Mater. 2000, 12, $527-$ 530.

[4] a) K.-S. Sohn, B. Cho, H. Chang, H. D. Park, J. Electrochem. Soc. 1999, 146, 2353-2356; b) K.-S. Sohn, B. Cho, H. D. Park, Y. G. Choi, K. H. Kim, J. Euro. Ceram. Soc. 2000, 20, 1043-1051.

[5] B. M. Tissue, Chem. Mater. 1998, 10, 2837-2845. 
[6] a) C.-C. Lin, P. Shen, J. Non-Cryst. Solids 1994, 171, 281-289; b) J. Lin, D. U. Sänger, M. Mennig, K. Bärner, Mater. Sci. Eng. B 1999, 64, 73-78; c) H. X. Zhang, S. Buddhudu, C. H. Kam, Y. Zhou, Y. L. Lam, K. S. Wong, B. S. Ooi, S. L. Ng, W. X. Que, Mater. Chem. Phys. 2001, 68, 31-35.

[7] a) T. S. Ahmadi, M. Hasse, H. Weller, Mater. Res. Bull. 2000, 35, 1869-1879; b) B. L. Clark, D. A. Keszler, Inorg. Chem. 2001, 40, $1724-1725$.

[8] a) Q. H. Li, S. Komarneni, R. Roy, J. Mater. Sci. 1995, 30, 2358 2363; b) S. W Lu, T. Copeland, B. I. Lee, W. Tong, B. K. Wagner, W. Park, F. Zhang, J. Phys. Chem. Solids 2001, 62, 777-781; c) C. Yoon, S. Kang, J. Mater. Res. 2001, 16, 1210-1216.

[9] K. Su, T. D. Tilley, M. J. Sailor, J. Am. Chem. Soc. 1996, 118, 34593468 .

[10] a) R. Morimo, R. Mochinaga, K. Nakamura, Mater. Res. Bull. 1994, 29, 751-757; b) Y. C. Kang, S. B. Park, Mater. Res. Bull. 2000, 35, 1143-1151; c) I. W. Lenggoro, F. Iskandar, H. Mizushima, B. Xia, K. Okuyama, N. Kijima, Jpn. J. Appl. Phys. 2000, 39, L1051-L1053; d) T. Tani, L. Mädler, S. E. Pratsinis, Part. Part. Syst. Charact. 2002, 19, 354-358.

[11] S. Seifried, M. Winterer, H. Hahn, Chem. Vap. Deposition 2000, 6, 239-244.

[12] S. Suh, D. M. Hoffman, L. M. Atagi, D. C. Smith, Chem. Vap. Deposition 2001, 7, 81-84.

[13] a) F. Schindler, H. Schmidbaur, U. Krüger, Angew. Chem. 1965, 77, 865; b) F. Schindler, H. Schmidbaur, Angew. Chem. 1967, 79, 697708.

[14] a) M. Driess, K. Merz, S. Rell, Eur. J. Inorg. Chem. 2000, 2517 2522. b) It should also be noted that the temperature inside the evaporation furnace was slowly varied from $60^{\circ} \mathrm{C}$ to $140^{\circ} \mathrm{C}$ over a period of $72 \mathrm{~h}$, in order to keep the precursor concentration in the gas phase constant during CVS experiments. This can be monitored by means of the particle number concentration, which was measured by using a condensation nucleus counter.
[15] a) M. Driess, K. Merz, R. Schoenen, S. Rabe, F. E. Kruis, A. Roy, A. Birkner, C. R. Acad. Sci. Ser. IIcC. R. Chimie 2003, 6, 273-281; b) J. Hambrock, S. Rabe, K. Merz, A. Birkner, A. Wohlfart, R. A. Fischer, M. Driess, J. Mater. Chem. 2003, 13, 1731-1736.

[16] a) L. Weber, H. R. Oswald, J. Mater. Sci. 1975, 10, 973-982; b) N. Taghavinia, G. Lerondel, H. Makino, A. Yamamoto, T. Yao, Y. Kawazoe, T. Goto, Nanotechnology 2001, 12, 547-551.

[17] Y. Syono, S-I Akimoto, Y. Matsui, J. Solid State Chem. 1971, 3, 369380.

[18] a) S. H. Ehrman, S. K. Friedlander, M. R. Zachariah, J. Aerosol Sci. 1998, 29, 687-706; b) T. T. Kodas, M. J. Hampden-Smith, Aerosol Processing of Materials, Wiley-VCH, New York, 1999.

[19] A. N. Goldstein, C. M. Echer, A. P. Alivisatos, Science 1992, 256, $1425-1427$.

[20] a) A. M. Pires, M. R. Davolos, Chem. Mater. 2001, 13, 21-27; b) M. S. Tomar, R. Melgarejo, J. Mater. Res. 2001, 16, 903-906; c) C.-C. Lin, P. Shen, J. Non-Cryst. Solids 1994, 171, 281-289; d) C. Cannas, M. Casu, A. Lai, A. Musino, G. Piccaluga, J. Mater. Chem. 1999, 9, 1765-1769. e) In the case that $\mathrm{ZnO}$ would be responsible for this UV-absorption, the estimated crystal size would be $7 \mathrm{~nm}$, and thus correlates quite well with the size of the $\mathrm{ZnO}$ nanocrystals found by XRD, TEM, and HRTEM (see below) (E. A. Meulenkamp, J. Phys. Chem. B 1998, 102, 5566-5572).

[21] M. R. Zachariah, M. J. Carrier, J. Aerosol Sci.J. Aerosol. Sci. 1999, 30, 1139-1151.

[22] M. Handke, M. Urban, J. Mol. Struct. 1982, 79, 353-356.

[23] a) J. A. Kitchener, S. Ignatowicz, Trans. Faraday Soc. 1951, 47, 1278-1286; b) A. Navrotsky, J. Inorg. Nucl. Chem. 1971, 33, 40354050 ; c) E. Jak, S. Degterov, P. Wu, P. C. Hayes, A. D. Pelton, Metall. Mater. Trans. B 1997, 28B, 1011-1018.

[24] F. E. Kruis, K. Nielsch, H. Fissan, B. Rellinghaus, E. F. Wassermann, Appl. Phys. Lett. 1998, 73, 547-549. 